R. Histórla, Sáo Paulo, D. 127-128, p. 97-113, ago-dez/92 a jan-jul/93.

\title{
SAÚdE E EDUCAÇÃO PARA O TRABALHO EM SESINHO (1947/1960) *
}

\section{Olga Brites **}

RESUMO: Este artigo aborda alguns materiais da revista infantil Sesinho sobre Sadde, Educaçăo e Trabalho. Ele destaca ligagbes entre tais temas e projetos gerais do SESI para infancia e sociedade brasileiras de 1947 \& 1960 .

PALAVRAS CHAVE: Infância, Saude, SESI, Sesinh Educaçăo.

A revista infantil Sesinho foi publicada pelo SESI (Serviço Social da Indústria), no Rio de Janeiro, dirigida por Vicente Guimarães, Autor de Literatura Infantil no periodo'.

A publicação, nesse sentido, foi órgão de divulgação do próprio SESI. A infancia era seu público privilegiado, demonstrando como aqueles empresários da indústria, que dirigiam o SESI, possuíam uma política para essa faixa etária, visando à constituição de uma modernidade produtiva para a nação brasileira e preservando certos valores que, em sua perspectiva, seriam garantia de progresso, caso de Religiosidade, Leitura e Cuidados com a Saúde. Caberia aos filhos de trabalhadores da indústria, desse ponto de vista, assimilarem e praticarem tais ensinamentos.

A revista era dirigida para filhos de trabalhadores da indústria, distribuída pelo próprio SESI em suas sedes e em escolas de $1^{2}$ grau, além de ser também vendida regularmente em bancas de jornal. Seu público leitor, por-

- O presente artigo retoma questóes tratadas na Dissertação de Mestrado Infancia Trabalho e Educaçāo defendida na PUC/SP, sob a orientaçăo da Prof" Dr" Dea Ribeiro Fenelon, que contou com financiamento da FAPESP.

- (Depto. de História da FCS/PUC-SP)

1 BRITES, Olga - "História e Educaçáo em 'Sesinho'". Revista Brasileira de História. Săo Paulo, ANPUH/Marco Zero, 9(19): 57/80, set 1989/fev 1990.

Idem - Infância, Trabalho e Educação - A revista "Sesinho" (1947/1960). Dissertaçăo de Mestrado em História, apresentada à PUC/SP. S̊̊o Paulo, datiloscrito, 1992. 
BRITES, Olga. Sadde e educação para o Irabalho em Sesinto (1947/1960).

tanto, não se restringia às famílias de trabalhadores da indústria, embora tivesse as mesmas como principal público-alvo e contribuísse para confirmar um projeto do SESI para formaçāo da classe trabalhadora no Brasil.

A concepção de Saúde com que trabalho neste artigo procura politizar o tema, abordando-o enquanto importante dimensão de outras práticas sociais, como Educaçāo e Trabalho. Procuro enfrentar a diluição de conflitos pelo periódico, que visava a harmonizar aquelas práticas, como se a aceitação das mesmas fosse garantia de felicidade para os trabalhadores.

Sesinho deu grande destaque à Saúde enquanto aspecto fundamental na formaçäo do cidadão brasileiro para o trabalho, configurando face do poder que os empresários possuíam, expressando o caráter assistencialista do SESI e destacando tais elites empresariais da indústria como verdadeiras realizadoras do bem-estar social, diferenciadas de elites políticas tradicionais e pouco empreendedoras.

A Saúde, em Sesinho, nà̃o era apenas a do corpo, ela reforçava dimensões do ser social - Estudo, Lazer, Físico e Espírito -, a serem trabalhadas na formaçāo do cidadāo.

A série "O dia de Sesinho", publicada desde o primeiro número da revista até sua edição de janeiro de 1949 (n² 14), é significativa para discutir a Educaçāo como tarefa de grande importância na vida da criança de família operária. Ela planeja o cotidiano infantil a partir de procedimentos integrantes de uma Educação para o trabalho e uma Educação integral.

A Educação para o Trabalho se preocupava com a formação de mãode-obra, tanto treinando habilidades (desenho, pintura, costura, etc.) como incentivando o leitor a definir uma profissão, valorizando o trabalho como bem fundamental para a nação brasileira. A Educação Integral abrangia múltiplos campos de saber e sociabilidade (diferentes disciplinas escolares, viver em família, papéis de gênero, viver em cidade, religiosidade, lazer, leitura, valores, sentimentos).

Foi através do personagem Sesinho que a série propôs para o leitor a formação de uma espécie de álbum: colorindo as páginas mensais publicadas sob aquele título, ele era convidado a participar do planejamento e disciplinarização de seu próprio tempo.

Logo no $n^{\circledR} 1$ do mensário (dezembro de 1947), a seção apresentou desenho com Sesinho levantando da cama, raios de sol penetrando no quarto, despertador disparando. $O$ texto referente a essa situaçāo colocou:

\footnotetext{
"Sesinho sente alegria

em ser madrugador.
} 
R. Hist6́ria, Såo Paulo, n. 127-128, p. 97-113, ago-dez/92 a jan-jul/93.

Bem cedo começa o dia

para o bom trabalhador."

A referência inicial para o personagem, portanto, foi o trabalho, seu cotidiano se estruturou para as crianças em função dela.

Os números do periódico que se seguiram abordaram naquela seção o ato de escovar os dentes como próprio à criança inteligente $\left(\mathrm{n}^{\mathrm{Q}} 2\right.$, janeíro de 1948), tomar banho cedo como fonte de força e prazer $\left(n^{2} 3\right.$, fevereiro de 1948), alimentos fundamentais na primeira refeição do dia - leite e pão - $\left(\mathbf{n}^{\circ}\right.$ 4, março de 1948), numa sequência cronológica do dia, mais dedicada ao cuidado com o corpo.

Os temas tratados do $\mathrm{n}^{2} 5$ ao $\mathrm{n}^{2} 7$ de Sesinho naquela série deram maior realce ao cuidado com o saber no cotidiano da criança, que não foi desligado da atençāo com o corpo. Assim, o personagem apareceu indo para a escola, levando livros e merenda, destacando-se dentre aqueles o volume de Física ( $\mathrm{n}^{2}$ 5, abril de 1948), sentado na sala de aula, com livro de Química aberto sobre a carteira $\left(\mathrm{n}^{2} 6\right.$, maio de 1948$)$ e jogando peteca durante o recreio ("艹 7 , junho de 1948), legitimando a sequência dever/lazer.

A continuação da série preservou o cuidado com higiene, alimentação, estudo e lazer, que garantiriam saúde e respaldariam outras atividades, com o personagem lavando as mãos ao chegar da escola ( $n^{2} 8$, julho de 1948), almoçando $\left(n^{2} 9 \text {, agosto de } 1948\right)^{2}$ e dormindo em rede após a refeição $\left(n^{2}\right.$ 10 , setembro de 1948 ).

Ele ainda teve tempo atribuído ao estudo em casa $\left(n^{2} 11\right.$, outubro de 1948), passeando para comprar jornal ou ir ao cinema após a atividade anterior ( $n^{2} 12$, novembro de 1948) e se preparando para o jantar, lavando novamente as māos, realçando o peso atribuído a higiene e alimentação na rotina infantil.

O desfecho da série englobou o cuidado com o espírito e um reencontro com o universo de suas tarefas: o personagem apareceu orando na hora de deitar, acrescentando-se que ele dormiria para descansar o corpo e melhor enfrentar novas lutas no dia seguinte ( $\mathrm{n}^{2} 14$, janeiro de 1949).

2 O texto desse exemplo e:

"Sesinho é forte e sadio,

Come bem e com fartura.

Seu almoço é leite frio,

Carne, arroz, feijåo, verdura". 
BRITES, Olga. Sadde e educaç⿰丿丶⿱⿴囗十丌 para o trabalbo em Sesinho (1947/1960).

A preocupação de Sesinho com a Educação e Trabalho, englobando Sacude $^{3}$, envolvia seus leitores de múltiplas formas, promovendo Concursos em que tais temas eram abordados, oferecendo premios aos melhores e escolhendo como vencedores aqueles que desenvolviam trabalhos que assimilassem seus projetos. Em março de 1949 ( $n^{2} 16$ de Sesinho), p. ex., Ila Marcondes de Vasconcelos, de 10 anos, aluna do $4^{2}$ ano primário, enviou à publicação biografia do médico Miguel Couto, destacando sua vida exemplar, origem modesta, mãe trabalhadora e competência profissional:

"Por mais de trinta anos, praticou a Medicina como uma Religião e vindo da pobreza própria passou pela pobreza alheia :s de morro em morro, de casebre em casebre".

Nesse exemplo, junto com o destaque à vida profissional, apareceu sua deđicação à Pátria, atuando na elịminação do analfabetismo, caracterizado como "praga sinistra que há muito tempo constitui calamidade espantosa para a nacionalidade", apontando a ignorancia como doença a ser eliminada, tendo como lema "saúde da alma pela educação e saúde do corpo pela higiene".

Observa-se nesse caso como uma questão remete a outras (Medicina, Profissão, Pobreza, Naçāo, Trabalho, Estudo), permitindo entender que o lema "Mente sã em Corpo são", muito presente em Sesinho, fazia parte do amplo universốt social abrangido pela atuação do SESI na assistência ao trabalhador e preparação para o trabalho.

No texto dessa leitora, portanto, o projeto geral de Sesinho apareceu explicitado: o cuidado com a alma, combatendo o analfabetismo, incentivando o gosto por leitura, estudo e tratando o corpo, prevenindo doenças, desenvolvendo práticas esportivas, alimentando-se adequadamente, repousando o necessário para repor energias, temas que "O Dia de Sesinho" expusera desde o primeiro número do mensário.

3 A preservaçáo da saude foi valorizada como atributo de crianças inteligentes, o que pode ser exemplificado por um poema publicado no $n^{\circ} 63$ do mensário (fevereiro de 1953):

"Menino prudente.

Todo meaiso prudente,

Educado, inteligente, Que sabe se comportar,

Em sua propria defesa, Antes de assentar-se d mesa, Val as móninhas lavar". 
R. Htstórta, Såo Paulo, n. 127-128, p. 97-113, ago-dez/92 a jan-jul/93.

Outra evidéncia đa atenção de Sesinho para o campo da saúde pode ser observada na série de pensamentos de Renato Kehl, publicada em sua capa interna em vários números de 1950. Esse médico higienista atuou no Brasil a partir da segunda década deste século, fundando na capital paulista, em 1917, a primeira Liga Eugenica da América do Sul, sendo responsável pela introdução do tema da Eugenia no panorama científico brasileiro. Em sua perspectiva, a Biologia tinha papel fundamental na solução de problemás sociais e da famflia; à Medicina Social, caberia o papel de criar uma geração de jovens "robustos e belos"; os fenômenos biológicos de degeneração da raça estariam condicionados ao meio.

Dessa forma, Kehl associou a Biologia às condiçōes económicas e sociais, cabendo à Medicina intervir para discutir "vícios", "venenos sociais", como bebida, sffiliss,' alimentação inadequada, moral, costumes, condições de trabalho e moradia, fatores que poderiam conduzir à "degeneração" da raça ${ }^{4}$.

Ao longo dos anos ' 50 , Sesinho publicou matérias sobre Concursos de Robustez na Infancia, promovidos pelo SESI. Em seu n² 136 (abril de 1959), fotos e texto registraram promoção dessa natureza em Cuiabá, MT, apresentando mães e filhos de tipos humanos diferenciados (brancos, Indios, negros), os mais comuns naquele estado, num projeto que devia atingir toda a população brasileira. Outro concurso similar, também no Mato Grosso, foi noticiado antes ( $n^{2} 110$, fevereiro de 1957), sendo sua Comissão Julgadora composta por duas mulheres, dois bispos, um padre e um diretor do SESI, demonstrando que mães, Igreja Católica e empresários da indústria estavam juntos naquela tarefa de constituir homens fortes.

A "Palestra de Vovó Felício" abordou questōes relativas a saúde através de conselhos sobre os cuidađos na hora de dormir com ventilação no quarto, vestimenta adequada, posição da cama, postura corporal, tudo isso remetido para a recuperaçāo de energias após o trabalho ( ${ }^{2} 53$, abril de 1952).

O personagem Sesinho apareceu na seção "Consultório Sesinho", sob a đireçẫo do Dr. Bicarbonato, sugerindo hábitos saudáveis como o controle do peso (considerou-se sadio o indivíduo de peso médio $-\mathrm{n}^{2} 50$, janeiro de 1952), cuidados com a pele e higiene ( $n^{2} 52$, março de 1952).

4 CUNha, Maria Clementina P. da. O espelho do mundo. Rio de Janeiro, Paz e Terra, 1987. ANTONACCI, Maria Antonieta. Vitória da Razäo?. Săo Paulo, Marco Zero, 1993. 
BRITES, Olga. Sadde e educaçăo para o trabalbo em Sesinho (1947/1960).

Transgredir padrōes colocados pelos adultos era desrespeitar hábitos de saúde como, p. ex., por os dedos no nariz, ser guloso, não gostar de tomar banho, etc.

O excesso na alimentação foi condenado por trazer perturbações gástricas e intoxicaçāo do sangue e o gelo tambem o foi por comprometer o estado dos dentes, além de prejudicar a digestão. Cuidados no convívio com animais domésticos transmissores de doenças foram recomendados, assim como mastigar bem os alimentos e trocar roupas íntimas ap6s o banho. Ao mesmo tempo, a revista recebia cartas de crianças doentes pedindo que exemplares da mesma lhes fossem enviados gratuitamente. Foi o caso de jovem tuberculoso, orfão de pai e mãe, hospitalizado: o SESI encaminhou educadora social ao hospital e a visita foi registrada fotograficamente, com a educadora social apertando a mão do rapaz e ele segurando exemplares do periódico na outra mãos.

Apesar das críticas a gulodice, houve momentos em que Sesinho possibilitou rir dos gulosos, tornando-os simpáticos aos público leitor. A seção "Rir de graça" (n 5, abril de 1948) narrou o seguinte episódio:

"A mãe diz ao filho: os biscoitos desapareceram da lata por culpa sua não é?

- Não mamãe, a culpa foi da maninha. Ela queria brincar com a lata. Entāo... para fazer-lhe a vontade, tive de comer todos os biscoitos, pará dar a lata vazia".

O cigarro sempre foi condenado como vício que atacava os pulmōes (p. ex., no $n^{2} 6$, maio de 1948 ).

A revista divulgou série de textos assinados pelo Serviço nacional de Educação Sanitária (SNES), órgão do Ministério da Educação e Saúde, criado em 1941 e que publicava muitos materiais sobre questões de saúde ${ }^{6}$.

As preocupaçōes de Sesinho com a Educação para a Saúde do trabalhador retomaram e consolidaram propostas presentes na sociedade brasileira desde o Estado Novo, como se percebe nas sugestōes do SNES e em balanço

5 As referéncias à tuberculose como grave doença contagiosa foram frequentes em Sesinho.

6 Alguns temas abordados nesses materiais: prevençấo (higiene pré-natal, cuidado com os dentes, evitar tracoma, cuidados com pele e visăo), doenças (tuberculose, retardamento, cfincer, esquistossomose, gripe) e vicios (tabagismo, álcool). 
R. Histórla, Săo Paulo, n. 127-128, p. 97-113, ago-dez/92 a jan-jul/93.

dos governos Vargas do período $1930 / 1945^{7}$. A questão da Saúde estava profundamente ligada, assim, à Educaçāo (recorde-se que, no governo federal, havia um Ministério de Educação e Saúde) e ambas participavam da formação para o trabalho e da assistência ao trabalhador e à sua família.

A publicação em livro do SNES abordou a alimentação do trabalhador, tema recorrente em Sesinho. Nela, o homem foi tratado como "utensílio de trabalho ou capital", "máquina humana" ${ }^{8}$. A partir dessa perspectiva, considerou-se que a alimentação correta precisava evitar escassez e excesso porque tanto um como outro prejudicavam a saúde e impediam a geração de riquezas.

Foram constantes os apelos nesse livro para a instrução naquela área, julgando a ignorância fator fundamental da má alimentação que tornava os sujeitos doentes e improdutivos e trazia prejuízos ao Estado, situaçảo que só poderia ser mudada por uma Educação eficaz:

"O quadro macabro de personagens esquálidos, anemicos e enfraquecidos, impotentes para o cultivo da terra e para a movimentação das indústrias, transformar-se-á logo em alegoria à labuta diuturna e alegre, com o homem robusto, de braço forte, preparando ambiente próspero, fecundo e pujante para o futuro glorioso da pátria"9.

Em ftem reservado aos erros da alimentação, salientou que o trabalhador nacional,

7 MES/SNES - Alimentaçāo do trabalhador. 5a. ed. Rio de Janciro, SNES, 1944 (escrito em 1939).

SCHWARTZMAN, Simon (Org.). Estado Novo, um Auto-retrato. (Arquivo Gustavo Capanema). Brasflia, C.PDOC/UnB, 1983.

8 Numa seç⿸̆𠃋 da revista, "As aulas de Tinoco" ( $n^{\circ} 64$, março de 1953), comenton-se que o crescimento e desenvolvimento da criança e a força e eficiência dos adultos eram enormemente dependentes do que comiam, alertando-se para o risco do excesso de alimentos. Além de ser um exemplo da concepçăo de estudar aliada a utilidade prática, o texto apresentou uma visăo do corpo como máquina, raciocinando em termos de produtividade e abastecimento com combustlvel adequado.

9 MES/SNES. Alimensação do trabalhador. Ediçăo citada.

Ztlia Lopes da Silva registrou a associação entre ignoráncia e má alimentaģa do tfabalhador em debates na Constituinte de 1933/1934:

SILVA, Ztlia Lopes da. O arcaico e o maderno na Constifuinte de 1933/1934. Tese de Doutoramento em História Social, apresentada na FFLCH/USP. Sáo Paulo, Datiloserito, 1991. 
BRITES, Olga. Sađde e educaçắo para o trabalho em Sesinho (1947/1960).

"quando não passa fome tem, permanentemente, fome qualitativa. O trabalhador come pouco e mal - feijảo, farinha, carne seca -, nāo tem energia, não pode produzir, não tem resistencia. Torna-se doente, transforma-se em peso morto para o Estado. A indolência e a falta de aptidāo para o trabalho não têm como causa o clima, mas sim a alimentação inadequada e insuficiente, que nāo đá vigor para o labor, nem defesa para a doença".

Essa postura se diferencia do determinismo que falava em "clima" como explicação para atraso e pobreza. O que se observa no texto é o peso significativo do social (alimentação inadequada por ignorância).

Seria importante, naquela perspectiva, criar programas adequados para atender aquelas necessidades, evitando problemas para o Estado e o empresariado.

Esse volume, além de indicar problemas na alimentação do trabalhador, sugeriu que repartiçỏes oficiais organizassem cozinhas e refeitorios que fornecessem alimentação correta e barata, fiscalizada por técnicos e especialistas competentes. Tais restaurantes deveriam ser "amplos, simples, modestos, arejados, claros, higienicos, limpos"10, com seçöes masculina e feminina, sendo apontadas vantagens para Estado e patrōes.

O SESI esteve articulado a essas preocupaçōes e Sesinho divulgou suas iniciativas.

Em dezembro de 1948 ( $n^{\circ} 13$ da revista), foi registrada a inauguração do Centro Social $n^{2} 1$ Presidente Dutra, localizado no campo de Săo Cristóvão, Rio de Janeiro. Estiveram presentes ao evento o Presidente da República, General Eurico Gaspar Dutra, o Diretor do Departamento Nacional do SESI, Engenheiro Euvaldo Lodi, e o Diretor da Divisão Regional do SESI, Dr. Castro Barreto. A notícia destacou que o Presidente ficou impressionado com a qualidade dos alimentos, elogiando o SESI, anunciando que a cozinha forneceria refeiçōes a preços baixos e que o Centro Social ofereceria à famflia de trabalhadores da indústria assisténcia pré-natal, lactário e ambulatório:

"Assim, num prazo relativamente pequeno, o SESI vai se organizando dentro de seu campo de açāo até alcançar completa-

10 MES/SNES. Obra citada, Ediçåo citada, p 82. 
R. Htstórla, Såo Paulo, n. 127-128, p. 97-113, ago-dez/92 a jan-jul/93.

mente sua finalidade que é a de assistir os trabalhadores na Indústria e respectivas famílias em suas necessidades de ordem económica, educativa e social. Em um ano e pouco de existência, o SESI já conta apreciável acervo de serviços prestados à classe que ampara, granjeando a confiança dos operários que o procuram, pois verificam serem suas promessas realizadas com presteza e eficiência".

Essa notícia demonstra vínculos entre as propostas do SNES para saúde e educação alimentar e os projetos do SESI nessa direção em todo o território nacional, atuação que apareceu, na perspectiva do órgão, como garantia de aproximação entre a classe trabalhadora e seus projetos, uma vez que foi destacada a eficácia na realização concreta de suas intençőes. O SESI apresentou imagens do empresariado dotado de ação e iniciativa referendadas por governo e trabalhadores, com o grupo empresarial intermediando os setores governamentais e do trabalho.

Um texto do SNES, publicado em Sesinho (n 13, abril de 1949), comentou:

"Há quem julgue alimentar-se otimamente porque, às refeiçōes, come peixe, carne, arroz, feijão e doce, regados com vinho ou cerveja. Mas a verdade é que se alimentou mal, pois deixou de comer legumes, frutas cruas, verduras, ovos e leite. Complete suas refeiçōes comendo também legumes, verduras, frutas, ovos, leite".

O campo temático abrangido pelo SNES alcançou, além de alimentos, cuidados com clima e uso ádequado de roupas, com unhas, dentes, falta de apetite e problemas de saúde causados pelo uso de balas e chocolates. Esses assuntos foram preservados em diferentes momentos de Sesinho, demonstrando sua integração com a trajetória geral do mensário e do SESI durante o período de sua publicação ${ }^{11}$.

11 Foram momentos que inclufram textos sobre utilidade dos animais (galo e galinba, $\mathrm{n}^{0} 111$, março de 1957), conselhos sobre ar puro (mesmo número) e necessidade de mastigar bem os alimentos ( $\mathbf{n}^{\circ} 134$, fevereiro de 1959), quadrinhos sobre castigo para criança que comeu doce apanbado do cháo ( $n^{\circ} 121$, janeiro de 1958), aulas de Ciências sobre sangue e doenças por falta de globulos vermelhos $\left(n^{*} 15\right.$, fevereiro de 1949) e contos em que animais procuravam conselhos médicos. A seção "Inimigos do homem" enfatizou o combate a animais nocivos - baratas, mosquitos, escorpiōes, etc. 
BRITES, Olga. Satde e etucaçlo para o trabalho em Sesinho (1947/1960).

O apoio aos esportes na revista fez parte também dessa atenção para com a saúde. Houve série de capas, de junho de 1949 (n 19$)$ a agosto de 1950 $\left(n^{2} 33\right)$, dedicada a diferentes modalidades esportivas. A ginástica foi valorizada como fator de embelezamento físico e fortalecimento do corpo, sendo ressaltada a necessidade de orientação para sua prática, feita por técnicos competentes. Identificou-se o SESI do Distrito Federal e seus congeneres nos diferentes estados brasileiros como orgãos que tinham o cuidado de fomentar - esporte com orientação segura, convidando os filhos de industriários a se inscreverem para sua prática graluita na entidade ${ }^{12}$.

Todas essas recomendações de Sesinho em relação à saúde fazem parte da Educação do trabalhador e de sua família, regulamentando seu cotidiano em relação a cuidados com corpo, capacidade produtiva, uma concepçāo de progresso e modernidade onde a Naçāo deve aparecer limpa, nutrida, forte, bela. Nessa perspectiva, a preocupação com a infancia $e$ fundamental pois significa construir um futuro mais seguro nessas dimensóes. Isto evidencia uma necessidade de orientar a infancia em diferentes campos porque essa faixa etária era concebida como aberta à assimilação de conhecimentos e criaçōes de hábitos. Através desse processo, anunciava-se a construção de uma infancia destitufda dos problemas que os adultos possuíam, reafirmando uma desqualificação dos trabalhadores adultos, anunciando o novo através das crianças adequadamente educadas.

E nesse contexto de uma infáncia saudável que se coloca o problema de sua orientaçăo para o trabalho.

Uma escolaridade que preparasse a criança para o mundo do trabalho náo era algo totalmente novo no Brasil de 1948/1949. Ela veio sendo produzida no pais ao menos desde os anos ' 10 , com a presença de escolas profissionalizantes que preparavam mão-de-obra qualificada para o exercício de alguns off́cios - mecanica, marcenaria, pintura, carpintaria, funilaria, etc. Observa-se mesmo um projeto social de "vincular o ensino profissional o mais possível com as necessidades da indústria e do setor económico mais desenvolvido da regiäo" (São Paulo) ${ }^{13}$.

12 Os ramos destacados naquele campo foram tênis, boxe, remo, esgrima, levantamento de peso, futebol, aataçăo, pesca, słate, salto com paraquedas, patios e bolinhas de gude.

13 RIBEIRO, Maria Alice Rosa. "Qualificaçáo da força de trabalbo: a experiencia das escolas profissionais do estado de Sáo Paulo (1911/1942)", in: RIBEIRO, Maria Alice Rosa (Coord.)-Trabalhadores urbanos e ensino profissional. 2a. ed. Campinas, EDUNICAMP, 1986, pp $119 / 223$. 
R. HLstória, Sáo Paulo, n. 127-128, p. 97-113, ago-dez/92 a jan-jul/93.

Uma das preocupaçōes centrais de Sesinho era a qualificação do trabathador, apontando novas dimensōes nas relaçōes próprias a esse campo. Em seu n 53 (abril de 1952), na seção "Pensamentos do mes", a revista publicou trecho de Euvaldo Lodi, empresário, engenheiro, té́rico da racionalização do trabalho e um dos fundadores do SESI:

"De nada vale falar em mecanização se não se criam os quadros de mecánicos e de operários acostumados a lidar com máquinas. De nada vale falar em racionalização de trabalho e em aumento de eficiéncia se não se infunde, no trabalhador, a consciência de que, através desse aumento de eficiência, ele resolverá os seus problemas individuais e terá aumentos efetivos de salários".

As máquinas apareceram aí como centro do processo de produçāo, às quais deviam se adaptar os trabalhadores e a técnica surgiu como garantia do social e mesmo principal aliada do trabalhador. A aprendizagem técnica, por sua vez, exigiria a assimilaçāo de valores em termos de identificaçāo plena. entre o trabalhador e a razão contida na máquina.

Houve uma justificativa indireta dos baixos salários através do argumento sobre despreparo dos trabalhadores no trato das máquinas. Ao mesmo tempo, os problemas dessa desqualificaçāo foram individualizados, como se devessem ser superados por cada trabalhador através do estudo.

Na sequencia desse texto de Lodi, na mesma edição do periódico, publicou-se o seguinte poema de João de Deus:

"A alma, como o diamante,

Sendo polida, é brilhante;

Em bruto, não luz, não brilha

Nâo se distingue da terra,

Não descobre a luz que encerra,

Não mostra de quem é filhan.

Os versos expressam a necessidade de polir, lapidar pedra e alma. No contexto para-didático da revista, esse lapidar tem o sentido de educar, disciplinar sob o signo da qualificação do trabalho e promoção inđividual. Trazer brilho e luz para o sujeito: assim se apresentaram Sesinho e SESI à infancia e ao trabalho.

Logo no primeiro editorial ( $\mathrm{n}^{2} 1$, dezembro de 1947), a revista demonstrou a importancia que atribuía a infáncia e preparação para o trabalho. $O$ 
BRITES, Olga. Sađde e educaçáo para o trabalbo em Sesinho (1947/1960).

texto se encerrou com a caracterização dos leitores como representantes da infancia industriária, que se preparavam para serem perfeitos técnicos industriais. Assim, a revista traçou um destino para os filhos de trabalhadores da indústria, destacando a necessidade de preparação técnica para se trabalhar nessa área.

Uma série de capas da revista, em sua etapa inicial, assumiu a tarefa de apresentar,para os leitores diferentes profissōes ligadas à indústria e, mais amplamente, à vida urbana, evidenciando sua preocupaçāo com uma Educaçăo voltada não só para o mundo fabril, como também para o viver em cidade $^{14}$.

Em diferentes profissões, Sesinho apareceu vestindo macacão e boné. A chave inglesa foi instrumento de trabalho presente em vários desses exemplos. Diferenças presentes nas capas derivaram da diversidade entre profissỏes, de acordo com instrumentos de trabalho, matérias-primas, insumos e outros apetrechos.

Nas diversas profissōes apresentadas, observa-se o cuidado quanto ao investimento do trabalhador: força física, levantar cedo, estudo. Seus ganhos foram definidos como morais e nunca se colocou a remuneração como fundamental. A utilidade de cada ofício foi vinculada ao seu caráter universalizante, que atendia a todos os grupos sociais. Isso pareceu dar maior legitimidade às profissões, desvinculando-as do interesse de um grupo social especifico - inclusive, dos trabalnadores.

As relaçōes entre Profissōes e corpo do Trabalhador foram estabelecidas tanto no nível de aptidōes para diferentes tarefas (força física para o ferreiro, gosto artístico para o pintor) como de cuidados com a saúde e marcas corporais deixadas pelo trabalho - calo do pedreiro, suor do carpinteiro, etc.

Foram atividades associadas a diferentes momentos da vida humana, casos do carpinteiro (đo berço ao caixão fúnebre) e do padeiro (produtos usados em refeiçōes simples, festas, piqueniques e até na missa). A remuneraçāo esteve submetida a outros valores julgados mais importantes, como honestidade, prazer na execução das tarefas, empenho e habilidade.

14 Tais capas foram publicadas de abril de $1948\left(n^{\circ} 5\right)$ a maio de $1949\left(n^{\circ} 18\right)$, comentando as profissóes em sua face interna: pedreiro ( $\left.n^{\circ} 5\right)$, carpinteiro ( $n^{\circ} 6$, maio de 1948), mecấnico ( $n^{\circ} 7$, junbo de 1948), pintor $\left(n^{\circ} 8\right.$, julho de 1948), ferreiro ( $n^{\circ} 9$, agosto de 1948), eletricista $\left(a^{\circ} 10\right.$, setembro de 1948 ), sapateiro ( $n^{\circ} 11$, ovtubro de 1948 ), padeiro $\left(a^{2} 14\right.$, janeiro de 1949), açougueiro $\left(n^{\circ} 15\right.$, fevereiro de 1949 ), vidreiro ( $n^{\circ} 16$, março de 1949), teceláo ( $n^{\circ} 17$, abril de 1949), e alfaiate ( $n^{\circ} 18$, maio de 1949). 
R. Histórła, Sāo Paụlo, n. 127-128, p. 97-113, ago-dez/92 a jan-jul/93.

De acordo com Sesinho, esses profissionais necessitavam de formação. Ela se dava, em alguns casos, através de cursos e livros e, noutros, pela experiência prática. Numa mesma profissão, como a de Mecánico, a revista admitiu a formação teórica, dominada pelos inventores (Santôs Dumont, p. ex.), e a existência de mecânicos práticos, hábeis artesãos que aprendiam em contato com a profissão desde a infância. Na profissão de ferreiro, enfatizouse essa aprendizagem de pai para filho.

Nessa discussão sobre profissōes, Sesinho articulou tradição e modernidade. Embora a revista se preocupasse com progresso e novas tecnologias, ela também assumiu o papel de garantir valores que precisavam ser preservados. A profissão de sapateiro foi defendida em sua dimensão artesanal e, naquele período, justificada por possibilitar economia ao trabalhador. Nesse sentido, não se tratava apenas, no periódico, de valorizar racionalização e mecanização do trabalho mas também de recuperar tradições que, nesse processo de mudanças, não podiam ser abandonadas.

A revista encaminhava os leitores para esses diversos ofícios, indicando locais de formação, como os cursos do SENAI, e advertindo para os riscos de algumas profissões (vidreiro, eletricista), destacando a legislação referente ao trabalho do menor em geral e naquelas áreas especificas.

Um exemplo significativo da profissão associada à formação escolar e técnicas mođernas é a de Tecelão.

O desenho de capa que configurou tal profissão ( $n^{2} 17$, abril de 1949) caracterizou Sesinho com seu habitual macacão, lendo um livro intitulado Tecelagem, sentado ao lado de grande tear. $O$ tecelão moderno teve seu ofício definido numa perspectiva histórica, caracterizado entāo pelo uso de máquinas avançadas, desempenhando menos tarefas manuais e necessitando de mais conhecimentos adquiridos nos livros, em oposição ao tecelâo antigo, marcado por maior dispendio de energia e pouca rentabilidade devido ao fuso è̀ roca.

O comentário de Sesinho sobre essa profissāo enfatizou que a indústria têxtil representava uma "das maiores fontes de riqueza do Brasil", indicando ser esse um importante setor de trabalho no país à época. A eficiência do trabalhador nesse ramo foi associada à sua capacidade técnica para socorrer as máquinas - em caso de sua paralisação, precisaria ligar fios para que voltassem a funcionar.

Outra importante referência ao operário téxtil argumentou que ele, sabendo desempenhar bem o seu papel, no anonimato, contribula para que ocorresse a "elevação econômica do Brasil", como se, na execução de suas tarefas, ele estivesse anônimo e se engrandecesse no final da mesma, integrando-se na nação e na produtividade, numa atitude da revista que submeteu a prática do trabalhador a esses valores. 
BRITES, Olga. Satde e educaçăo para o trabaibo em Sesinto (1947/1960).

O periódico assumiu certa distinção entre trabalho manual e intelectual, valorizando este último em nome da habilidade técnica, que dependia do ritmo de produção imposto pelas máquinas modernas.

Essa face da Educação para o trabalho esteve presente também em comemoraçóes do Dia do Trabalho, como em 1948, quando afirmou:

"A humanidade inteira presta no dia $1^{2}$ de maio significativa homenagem ao labor. Homenagem justa porque vivemos a era do trabalho. Já se foi o tempo em que somente pelejavam o escravo e a plebe. Os nobres e os ricos tinham vergonha de trabalhar. Hoje, porem, é o trabalho que constitui nobreza. Todos trabalham ricos e pobres, porque o trabalho não é só para visar remuneração. $O$ trabalho valoriza $o$ homem. Quem não trabalha E vagabundo e não merece o respeito da sociedade. A fortuna nāo exclui o dever de trabalhar. Mesmo porque, além de uma obrigação social, e o trabalho um prazer. $O$ homem que trabalha sente-se satisfeito consigo mesmo."

(Sesinho, $n^{2} 6$, maio de 1948).

\section{sobre o tema:}

A seguir, nessa mesma edição, a revista publicou versos de Guimarães

"Quem não trabalha é vadio,

É malandro, é preguiçoso,

Torna-se um doentio

Muitas vezes perigoso.

Com o trabalho ajudaremos

Nossa terra a progredir.

Trabalhemos, trabalhemos

Para o Brasil do porvir."

A ilustraçâo desses versos destacou aspectos do trabalho na infancia, com uma criança vendendo jornal e outra engraxando sapatos, demonstrando perspectivas de trabalho $\mathrm{ja}$ assumidas nessa faixa etária.

São textos que narram um novo tempo, de valorização do trabalho, que iguala pobres e ricos como sinonimo de nobreza ${ }^{15}$. O fundamento do trabalho foi a dignidade humana e executá-lo com alegria significava felicidade.

15 Sobre a constituiça do trabalho como valor positivo, cf:

ARENDT, Hannah. A condiçāo humana. Traduçăo de Rober to Raposo. Rio de Janeiro/Săo Panlo, Forense-Universitaria/Salamandra/EDUSP, 1981. 
Houve a oposição entre trabalho e não-trabalho, sendo o lugar do último caracterizado como doença, malandragem, preguiça e periculosidade, elementos desviantes que seriam corrigidos na sociedade do trabalho.

O trabalho foi, ainda, associado por Sesinho à vida, oposto ao não-trabalho, sendo este ligado à morte. Esse tema apareceu em fábula quadrinizada ( $\mathrm{n}^{2} 121$, janeiro de 1958), onde um velho cansado e reumático precisava carregar monte de lenha. Sentindo dificuldades para assumir seu trabalho, apelou à morte para que o levasse, dizendo achar triste que ela atingisse crianças, enquanto a vida de esforços, na velhice, era um fardo para ele. 0 susto diante da imagem da morte fez com que ele readquirisse forças para continuar seu trabalho, pedindo-lhe que o ajudasse a colocar o feixe de lenha nas costas e saindo em disparada: a morte abandonou a vida quando o trabalho foi recuperado.

O tema do trabalho oposto a valores improdutivos também se fez presente no conto "O sapo e a raposa", parte da série "O caçador de onça" ( $n^{2}$ 111, março de 1957). Nele, a raposa, muito vaidosa, apresentava-se como bela, corajosa e inteligente. Por este motivo, ela nāo aceitava trabalhar e roubava. O sapo era seu oposto, feio mas trabalhador. No final, ela foi morta pelo caçador porque fazia estragos no galinheiro enquanto o feio sapo, por ser útil, "mereceu viver mais anos".

A clássica narrativa "A cigarra e a formiga" apareceu em diferentes números da revista, incluindo reproduçāo de versos de Bilac:

\author{
"(...) \\ Carrega cada formiga \\ Aquilo que achou na estrada, \\ E nenhuma se faliga, \\ Nenhuma para cansada. \\ Vede! enquanto negligentes \\ Estão as cigarras cantando \\ Vão as formigas prudentes \\ Trabalhando e armazenando. \\ (...) \\ Recordai-vos todo o dia \\ Das liçōes da Natureza. \\ O Trabalho e a economia \\ São as bases da riqueza."
}

O apelo aos animais humanizados, dotados de valores como esforço, prudéncia, persisténcia, defesa de riqueza via trabalho e economia, teve por 
BRITES, Olga. Saude e educaçăo para o trabalho em Sesinho (1947/1960).

contrapartida a apresentação da Natureza como mestra, que transformou aqueles valores em dimensōes inquestionáveis - porque naturais - da vida. $\mathbf{A}$ apresentação desses valores para as crianças exemplifica a importancia do projeto enciclopédico do periodico também como definição de um universo coerente e articulado a partir de determinados modos de viver. Trata-se de procedimentos clássicos na Literatura Infantil, reiteradamente trabalhados em Sesinho.

Os valores explorados por Sesinho em Saúde, Trabalho e Educação propunham-se a repor uma condiçáo natural da vida proficua e produtiva. Assim como na Natureza tudo funcionava harmoniosamente, as relaçōes na sociedade poderiam atingir um ponto de equilíbrio apelando para aqueles valores.

Tal preocupação no que diz respeito à Saúde para o Trabalho se refletiu tambem na condenaçāo de vícios considerados negativos, como o cigarro. Personagens julgados positivos jamais fumaram, mantendo a saúde do corpo, bem como não leram textos ou assistiram a filmes avaliados como prejudiciais à saúde do espírito. Histórias em quadrinhos e seus heróis mereceram condenação por Guïmarāes no livro Vida de rua ${ }^{16}$.

Famflia e: Escola foram tratados como alvos e núcleos fundamentais para a instituição daqueles valores, sendo através das mesmas que a criança receberia a formação cotidiana para orientar sua vida no presente, garantindo um futuro para a nação saudável.

Os graves problemas que se observam no Brasil de hoje em Saúde e Educação nas famílias operárias ajudam a entender que os argumentos do SESI tiveram um papel maior de legitimar poderes patronais, o que não significa inexistencia de preocupaçōes com crianças e adultos da classe trabalhadora na medida em que manifestaçōes e movimentos desse grupo social poderiam fugir ao controle de empresários e órgãos governamentais.

Vale lembrar que SESI, SESC, SENAI e SENAC surgiram num contexto de lutas e manifestaçōes de trabalhadores, como grandes greves apontadas por Weffort ${ }^{17}$.

Os empresários discutiram Saúde, Educaçāo e outros f́tens como evidéncias de falta de vontade ou ignorancia dos trabalhadores quanto à sua

16 GUIMARÃES, Vicente. Vida de rua. Rio de Japeiro, sem indicaçắo de Editora, 1954.

17 WeFFORT, Francisco $C$. "Democracia e movimento operário: algumas questócs para \& História do perlodo 1945/1964". Revista de Cultura Contemporánea. Sáo Paulo, I (1 + 2): $7 / 13$ + 3/11, jul 1978 + jan 1979 + Revista de Cultura Polftica. Såo Paulo, I (1): 11/18, ago 1979. 
R. Hist6rla, São Paulo, n. 127.128, p. 97-113, ago-dez/92 a jan-jul/93.

superação. Ler Sesinho não significava, todavia, apenas incorporar esses horizontes: cartas de leitores demonstraram também suas relações criativas $e$ críticas com a publicação, junto com assimilações daquele projeto.

ABSTRACT: This articte comments on some materials of the children's magazine Sesinho about Health, Education and Labor. It emphasizes the connections between such topics and general projects of SESI for childhood and Brazilian society from 1947 to 1960.

KEY - WORDS: childood, health, SESI, Sesinho, education. 